\title{
NECROLÓGICA
}

\section{VÍCTOR SEGOVIA PINTO}

(1925-1995)

\author{
Miriam Beatriz Rios Meneses \\ Centro Regional Yucatán, INAH
}

El 7 de diciembre de 1995 podríamos decir que ocurrió un eclipse en la ciudad de Mérida, ya que el valioso arqueólogo yucateco Víctor Segovia Pinto, quien se dedicó a la arqueoastronomía maya los últimos katunes de su vida, falleció víctima de breve dolencia a la edad de 70 años.

Pionero de la arqueología yucateca y apasionado investigador de la cultura maya, catedrático y descubridor de fenómenos arqueoastronómicos en edificios prehispánicos de la península, el arqueólogo Víctor Segovia nació en esta capital el 21 de noviembre de 1925, siendo sus padres José Ángel Segovia González y Mercedes Pinto Ramírez. Realizó sus primeros estudios en el Colegio Montejo y en la Escuela María González Palma de Ávila, cursó el bachillerato en la Preparatoria Libre, donde destacó en el estudio de las ciencias sociales, lo cual le valió una beca de la Liga de Acción Social de Yucatán para llevar a cabo estudios superiores en la Escuela Nacional de Antropología e Historia, en la ciudad de México.

Víctor Segovia realizó numerosas exploraciones de campo al lado de destacados investigadores nacionales y extranjeros en distintas regiones del país, pero sobre todo en el área maya. En 1955 participó en las excavaciones de Palenque dirigidas por el arqué́logo Alberto Ruz Lhuillier; un año después, en Comalcalco, Tabasco, fue asistente del doctor Gordon Ekholm del Museo de Historia Natural de Nueva York. De 1957 a 1958 retornó a Palenque, continuando su colaboración con el doctor Ruz Lhuillier. En 1959 formó parte del equipo que exploró las grutas de Balankanché, coordinado por E. Wyllys Andrews IV. Posteriormente trabajó en Yagul, Oaxaca, con el doctor Ignacio Bernal, y en Michoacán, bajo las órdenes del arqueólogo campechano Román Piña Chan. 


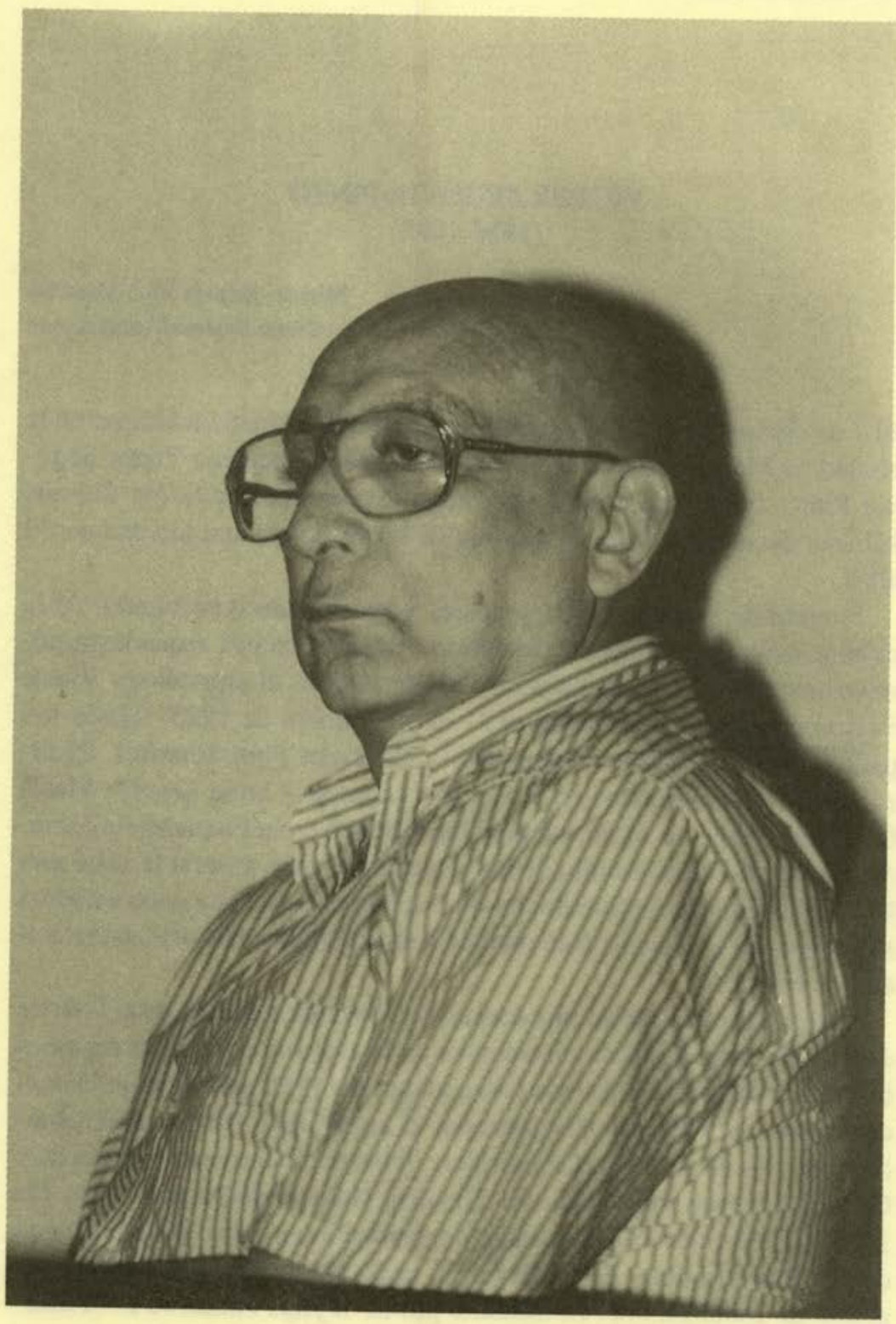

Víctor Segovia Pinto (1925-1995)

Estudios de Cultura Maya. Vol. XX, 1999 Instituto de Investigaciones Filológicas/ Centro de Estudios Mayas, UNAM ISSN 0185-2574

httn://www iifilologicas unam mx/estculmaya/ 
Fue el primer arqueólogo en aventurarse a realizar una exploración subacuática en el Cenote Sagrado de Chichén Itzá en 1967, cuando esta actividad requería de un alto grado de preparación por el riesgo que implicaba. $\mathrm{Al}$ año siguiente, supervisó la consolidación parcial del edificio conocido como Kinich Kak Moo en Izamal, considerado como el cuarto basamento de mayor volumen en México. En 1969 realizó excavaciones en el sitio de Ekmul, cercano a Aké, donde localizó numerosos entierros. Asimismo, fue el primer arqueólogo yucateco que realizó trabajos de investigación y exploración en la zona de Dzibilchaltún, durante la década de los sesentas.

Entre 1969 y 1981 trabajó en la exploración y restauración de Kohunlich, en el sur de Quintana Roo, cuyo nombre deriva del traslape lingüístico de dos voces inglesas con pronunciación maya: Cohoon Ridge ('el risco Cohoon'); de 1982 a 1985 colaboró en las excavaciones efectuadas en la zona arqueológica de Tulum, actualmente una de las más visitadas. Destacan también sus trabajos de arquitectura del paisaje en los dos sitios antes mencionados, así como en Dzibilchaltún, Izamal y Uxmal; en Chichén Itzá la practicó en varios edificios y en el sacbé (camino sagrado) que une la parte norte de la pirámide de Kukulkán con el Cenote Sagrado, donde según fray Diego de Landa "en lo profundo de sus aguas moraba Chaac el dios de la lluvia".

El maestro Segovia ofreció también diferentes cursos sobre la civilización maya y arqueología en general. De 1961 a 1963 impartió cursos de verano en inglés en la Facultad de Filosofía y Letras de la UNAM; impartió clases en 1961 en la Universidad de Guadalajara, y un curso sobre arqueología general en la Universidad de Yucatán en 1967. Víctor - como era conocido no tan sólo por un reducido grupo de especialistas de la cultura sino por muchos yucatecos- era especialmente apreciado por los guías de turismo, a quienes les impartía año tras año cursos de superación y les explicaba con gran entusiasmo los descubrimientos que había realizado en la zona maya; él mismo acompañó como guía en sus visitas a las zonas arqueológicas de la península a numerosos jefes de gobierno, entre ellos la reina Sofía de España, al inaugurarse las obras de la Misión Española en Oxkintok en 1990.

Desde mediados de la decáda de los ochentas, Víctor Segovia trabajó estrechamente en los programas de investigación del Centro Regional Yucateco del INAH, donde tuvo oportunidad de realizar numerosos estudios que culminaron en el hallazgo de fenómenos arqueoastronómicos en diversos templos y construcciones prehispánicas. Fue él quien descubrió este tipo de fenómenos en el Templo de las Siete Muñecas de 
Dzibilchaltún, que marca los equinoccios y solsticios; en el Palomar, donde se proyecta la sombra de una serpiente durante los solsticios, en el Palacio del Gobernador de Uxmal, donde ocurre el fenómeno conocido como cunkú (cuando el sol se detiene marcando el inicio del verano), así como en otros edificios de Tulum, Kohunlich y El Rey (Cancún), además de la llamada "serpiente lunar" en Chichén Itzá. En relación con ello, fue uno de los primeros investigadores que estableció la relación entre los fenómenos arqueoastronómicos de Mesoamérica con los que se han identificado en la antigua Mesopotamia.

En 1990 el investigador recibió la Medalla Yucatán por sus importantes aportaciones a la arqueología yucateca, que más tarde donó a la Liga de Acción Social. Su última aparición en público fue el 30 de octubre de 1995, cuando acompañó al presidente de Estonia en su visita a la zona arqueológica de Uxmal.

Se nos fue Víctor sin poder realizar completamente sus grandes sueños de continuar estudiando los fenómenos de luz y sombra que se presentan en los edificios prehispánicos de la mayoría de las ciudades del mundo maya, durante los solsticios y los equinoccios; tampoco pudo completar a cabalidad sus estudios de arquitectura del paisaje entre los mayas, quienes convertían sus ciudades en preciosos jardines.

\section{Bibliografía}

HUCHIM HERRERA, JoSé

1990 "Semblanza del arqueólogo Víctor Segovia Pinto", en I'inaj, época 1, núm. 1, Centro Regional Yucatán del INAH, Mérida.

Morales ValderRama, Carmen

1990 "Hallazgos arqueoastronómicos del 89. Entrevista en tres actos al arqueólogo Víctor Segovia Pinto", en I'inaj, época 1, núm. 1, Centro Regional Yucatán del INAH, Mérida.

Rfos Meneses, Miriam Beatriz

1995 Los mayas, pasado y presente, Seminario de Cultura Mexicana, Centro Regional Yucatán del INAH, Mérida.

Segovia Pinto, Víctor

1981 Kohunlich, Secretaría de la Presidencia, México. 